
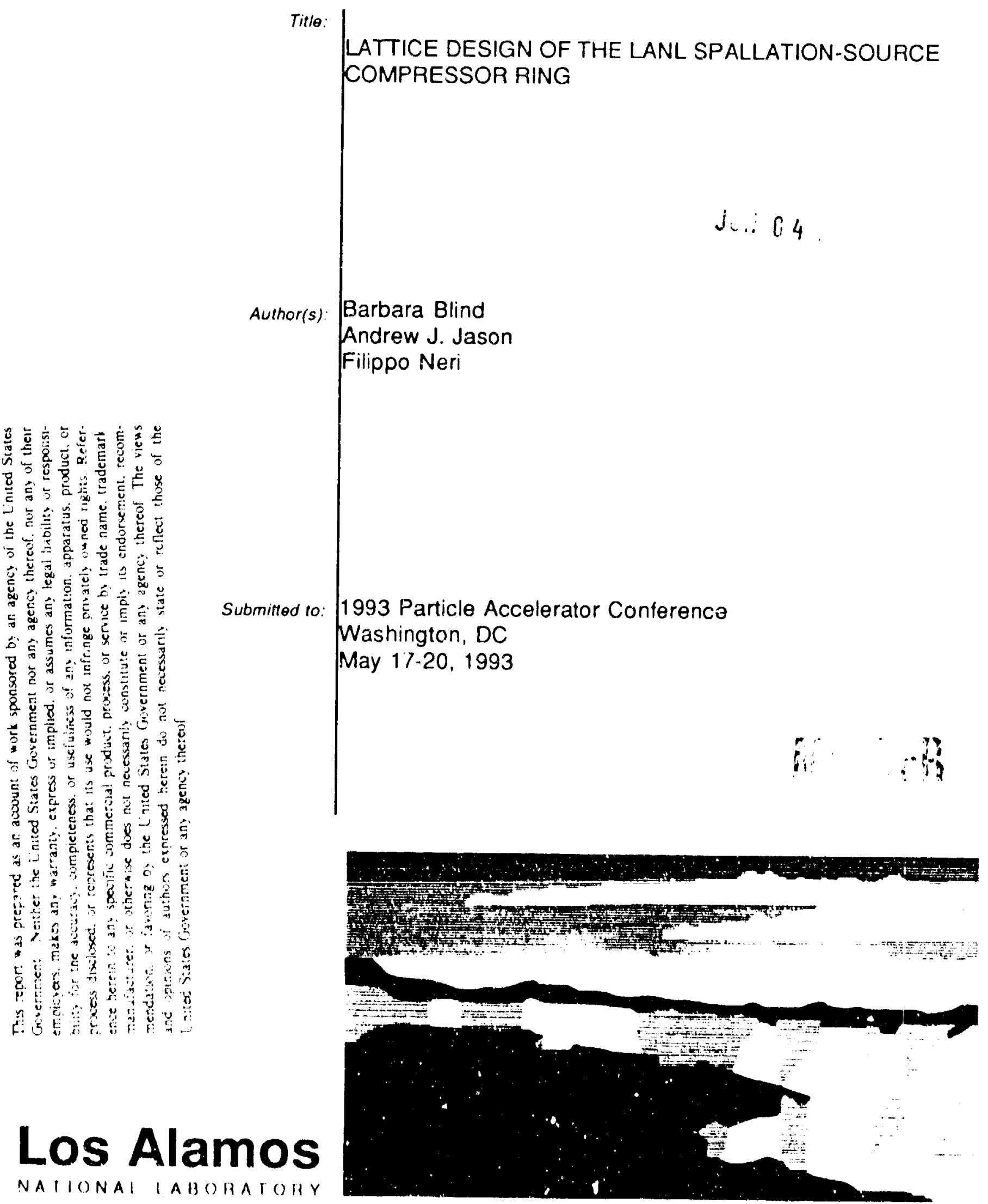

NAIIONAIIABOHATOHY

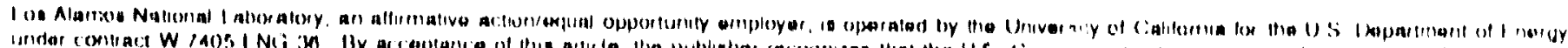

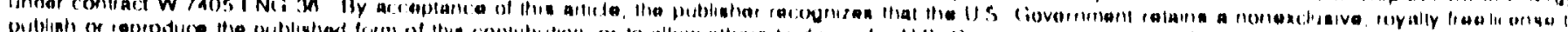

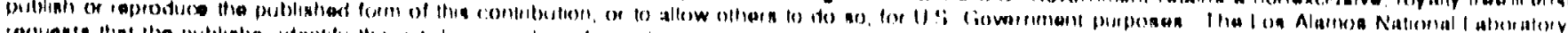

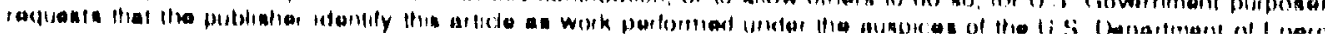




\title{
Lattice Design of the LANL Spallation-Source Compressor Ring*
}

\author{
Baroara Blind, Andrew J Jason, and Filippon Noro \\ los Alanos Natumal Laboralory

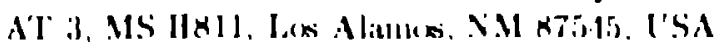

\section{Alsitract}

A new rompressor ring for 7 (n) Me. M protons is propossed at Los Alumos Nalunal Laboratory to provide I MW of beam power for a spallation-meuteon souree. 'The deMgn has unit-tralısfer-malrix achromat ic ares. Bunching, heant-control. and extraction elements reside in dispersiculiss straght sections. 'The are symmetry and further high-order corrections maximize lume space availalste to the beall. The rung-injertion scheme use's dirent $I^{-}$injection and care is taken in disposing of the unstrippend and partially stroppert beans. The lateice design allows for transverse" phase'space painting to maximuze particle slorige", as will as mimmize slured-beam foil traversals.

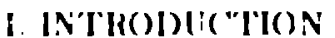

The ring is just one component of a proposed upgriude of the Los Alamos Meson Physues Facility (LAMPP) [1]. designed to deliver $1 \mathrm{MW}$ of beam power to two target stalions operating al $1011 \%$ and 20 Il\%, respectively. "The" 1.2-114 L.AMIP' pulse must be delivered to the ring in an irregular pattern (i) times per second; pulsed devices must

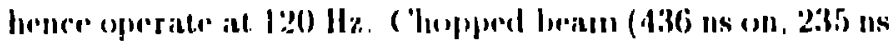

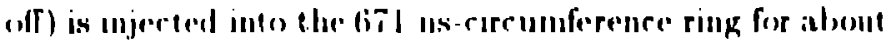

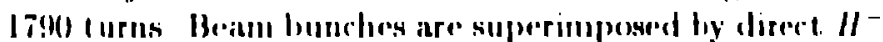
injertion. A gap is maintaned by an rf systern consistung of I weelve cavilles operelelly at first through fifth rang har

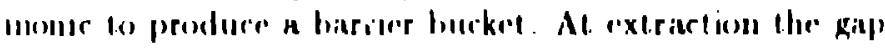

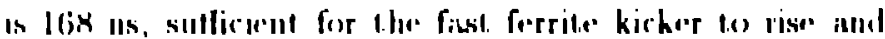

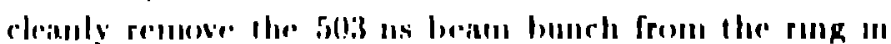
sligs.-t.urn extractla,
A ring energy of 790 Me. 1 was chosen, evell thungh the LAMI'F arceleralor nominally delivers $H^{-}$of because beam energy will be swept with the lisil k():-.Mlly. side-roupled luar tank by \pm 4 MeV durmg mjerlinn.

The rang circumference of Itik.8Xti un wis rhosell so lhal the revolution frequency for 790(0-M.V protonls is a subhat monic of to5) Mllz; additonally; all five harrier-huckel rf

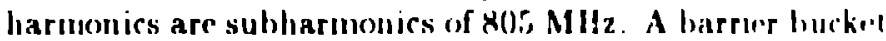
was chosen for its abslity to keep the gap heram frere, avoiding extraction losses as well as a possible e-p instabilits. and bec ause it allows phaximum beall capture and pror vides a bunching factor (average rurrent/peak curren!) of (1.55). compared to 0.25) for a lirst-harmonic cavity. The heall emillance necessary to keep the spaterechitge lume depression below a certiain value is inversely propertumal to this bunching, factor

\section{IRIN(;-I)HSICIN OVFIRVIFH}

'The ring is described in 'Table I and shown an Figure I.

Tiable I

Ring I)esign P'uramelers

\begin{tabular}{|c|c|}
\hline Fimergy (M.l') & $7 ! 11$ \\
\hline ('ircumference (m) & $\operatorname{lin} \times x \operatorname{~in}$ \\
\hline Rrperteten Hate (Hza) & $.41)+2(1$ \\
\hline Particles Pיer Pulas & $132 \quad 10^{1 \cdot 1}$ \\
\hline Number of ( iells in Arhromalic Arr & .1 \\
\hline 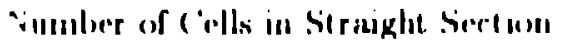 & $i$ \\
\hline 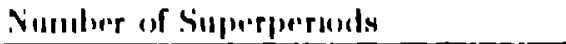 & 2 \\
\hline
\end{tabular}

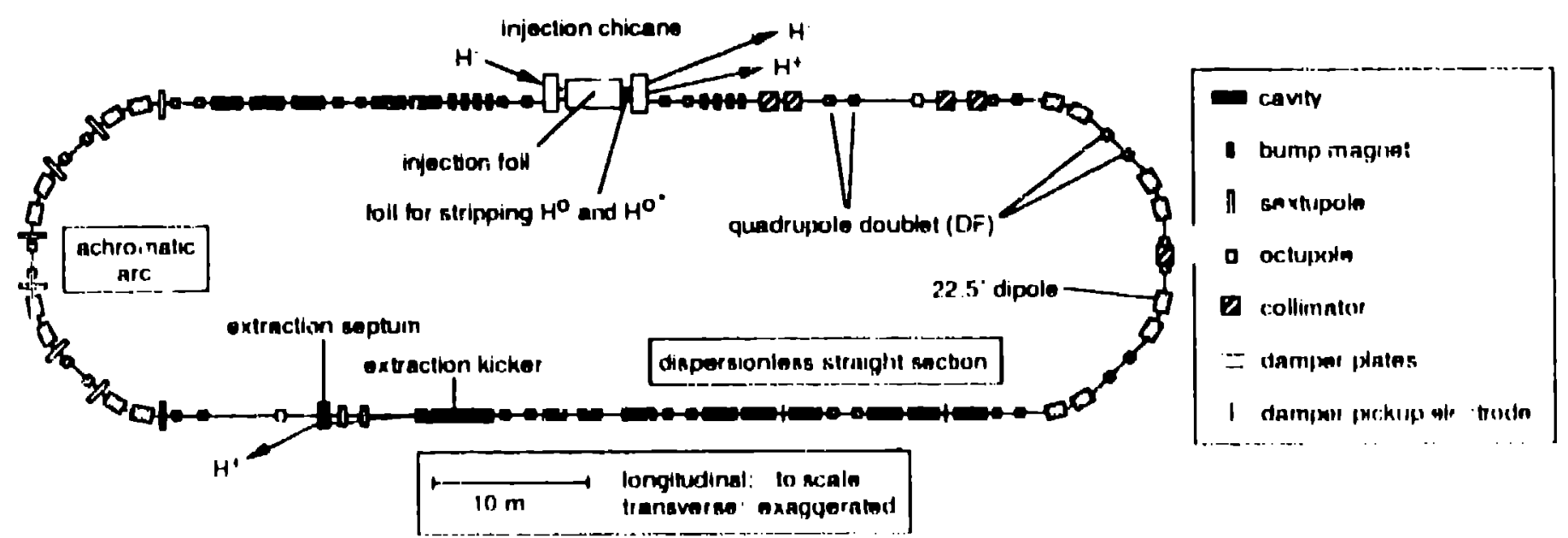

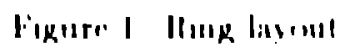

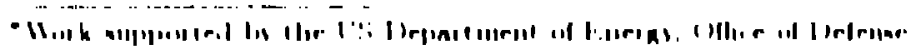

l'inkin nuth 
it features despersionless st rillght sectlolls alld are's ill the configuration of second-order athromils. Siraight sectluns house the injecton cherame, bumi magnets for injertun pauntung collimal ors for heam-halu control. bunchung cav llies, a t.ransverse-damper system, linn ar and l nonlinear cor rector elements, and the "xtraction kicker and extracturn septum. (One achromatic are housess sextupoless. the ot her a dhepersion collimat or. Beam pessit mon momors and rlowed. orbit-correcteol steerers are located throughout the ring.

The desire to arcomplish unjectum in a silugle drift mandatod a minimuen drift length of $* \mathrm{~m}$. 'Thus. toperther with arcs of the above-mentioned design, suggested a duublet as opposed to a singlet, latitice. Five cells per striught sectuon were chosen because of tune considrerations, because for the required ring circumference the long drifts are adequately dimentioned $(8.407 \mathrm{~m})$, and because the five long drifts in low-loss areas (upstrean of injection chicane and extraction kicker) can hold all rf ravities

\section{LINEAR IATIIT':}

'Ihe lattice functions of the ring, slightly different from

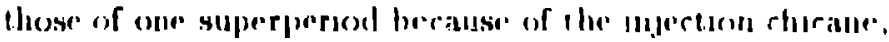
are shown in Figure 2. the lattice parameters are given iII Table 2. The machime tumes, $Q_{r}=1.23, Q_{y}=3.19$, correspond to phase advanres pere seraighte-serction cell of 80. $28^{\circ}$ and $11.48 .4^{\circ}$, respertively, Me:ar the value of $90^{\circ}$ that

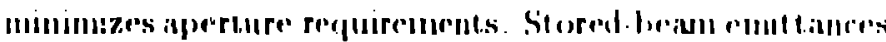

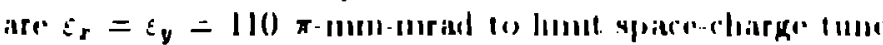

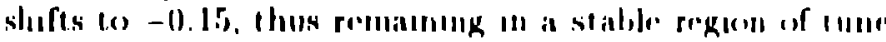
space. Apertures are dimensioned for transwerse accep

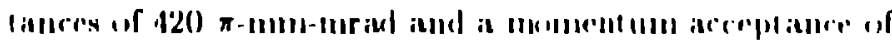

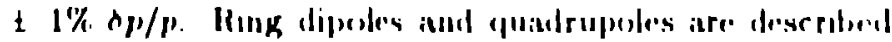
III lial, le? I

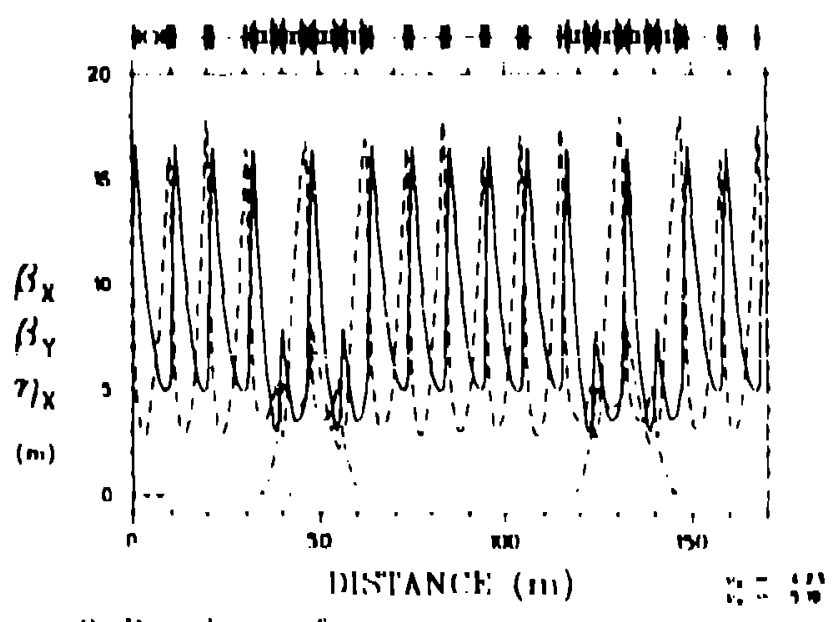

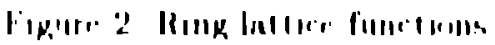

Iislik. :

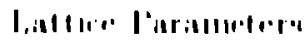

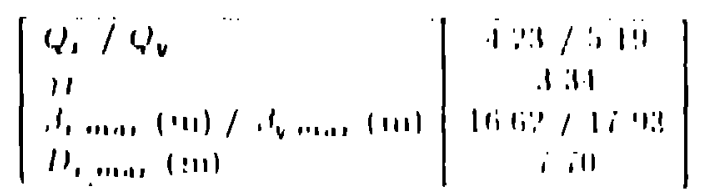

Iable. 3

Magnet Descruptutu

\begin{tabular}{|c|c|}
\hline 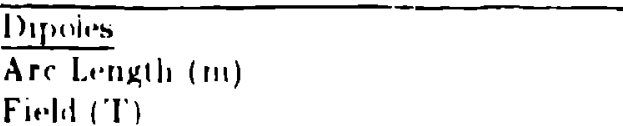 & $\begin{array}{l}1 \text { fivii) } \\
1 \text { Isix }\end{array}$ \\
\hline 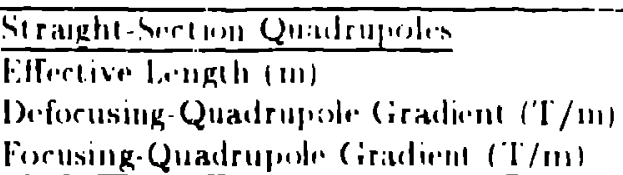 & $\begin{array}{r}11.3111 \\
-1.311 \\
3 ! 3 ! 11\end{array}$ \\
\hline 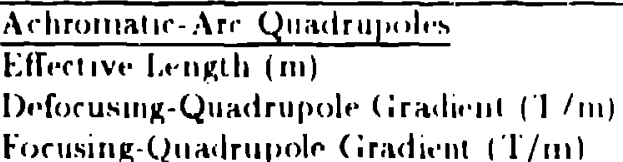 & $\begin{array}{l}11 \text { illu } \\
3 \text { liki } \\
1 \text { ?biti }\end{array}$ \\
\hline
\end{tabular}

\section{NONIINFAR ISTIES}

'The first-and second-order chromalicites anth the in

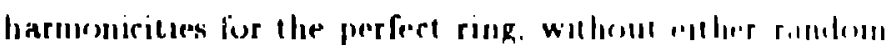
or systematic errors in the magnet ir elements. are gorll

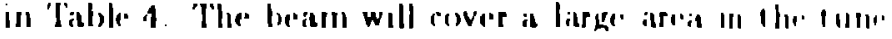

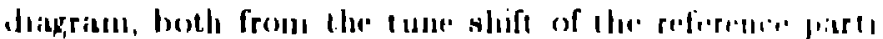

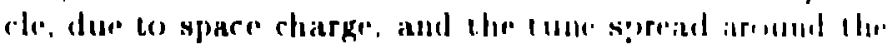

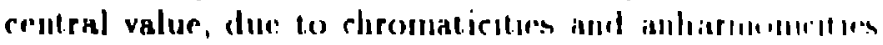

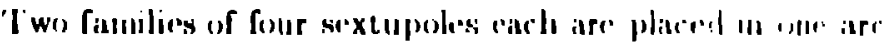

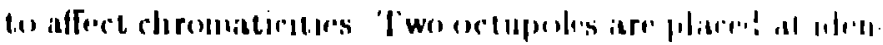

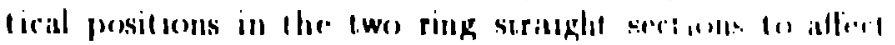
anharmonectues for cout rol of tune spresial

Talle. 1

Nemlinmar llung l'ieramelers

\begin{tabular}{|c|c|}
\hline 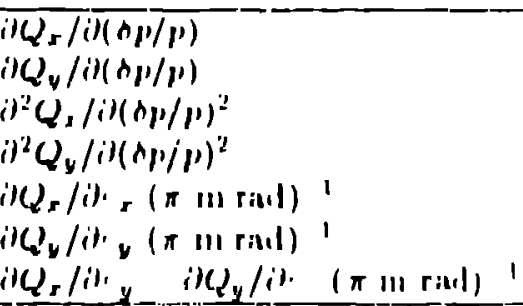 & 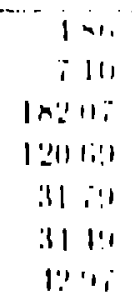 \\
\hline
\end{tabular}

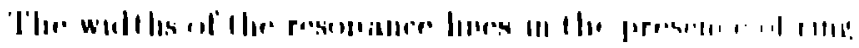

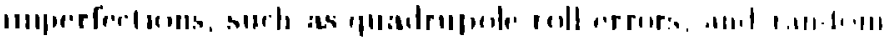

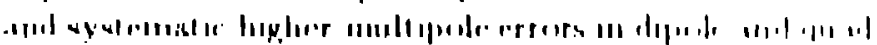

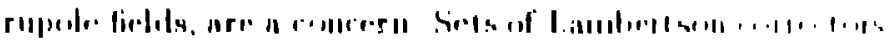

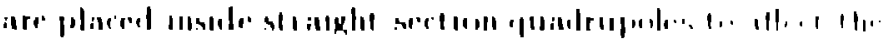

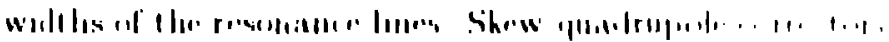

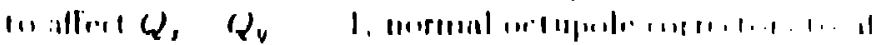

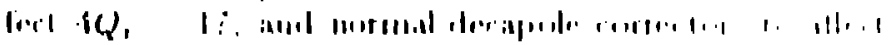

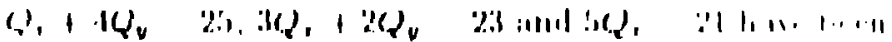
alentiliend

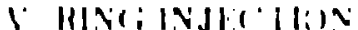

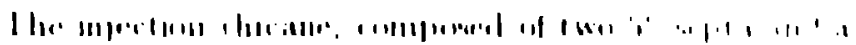

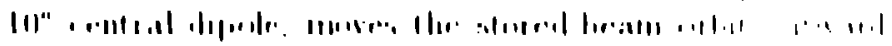

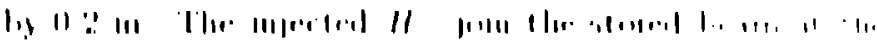

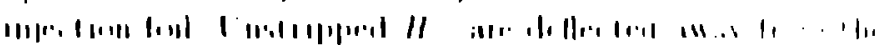
.

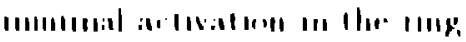




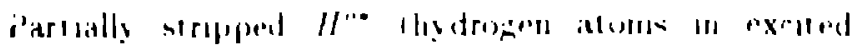

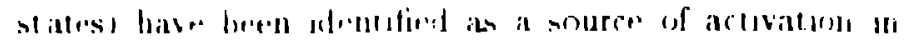

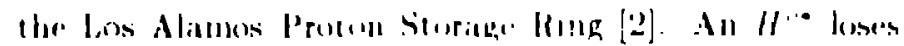
lis electron in a maguetic field of a strength llat depends oll guantum state. The $\|^{\prime \prime}$ lhus may be stroperd by a

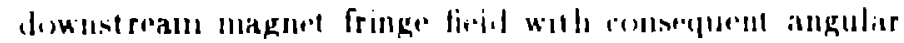

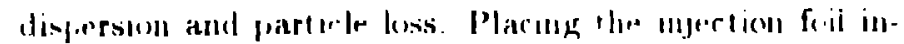
side a dipole field ran signiticantly redure the problem by strepmeng higher states lo remant withn the slored-heram rollllance 'llye lield value is sel wh hat lower states remaun exrited and can he dispensed of all a beam dump after

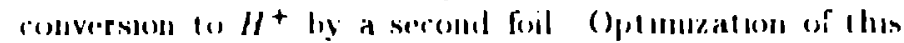
systould indicales that a miximum loss of $910^{-5}$ of the infected beam is an principlo achievialole.

figure 3 illostriates the muertion proresss. It show's the

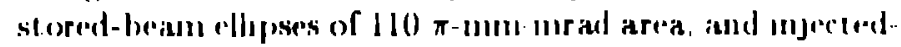
beall ellipses of $3.2 \pi$-mon-mrad $(1,2 \pi)$ areas. The injer. tun point (e), namely $s, s^{\prime}, y, y^{\prime}$ of the injertedluteam centroul, is stitionary (althengh heoul energy is swepl by

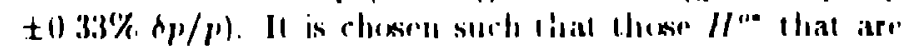

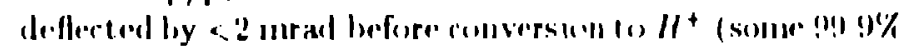

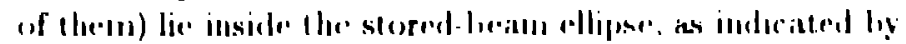
the shated arein in Figure is

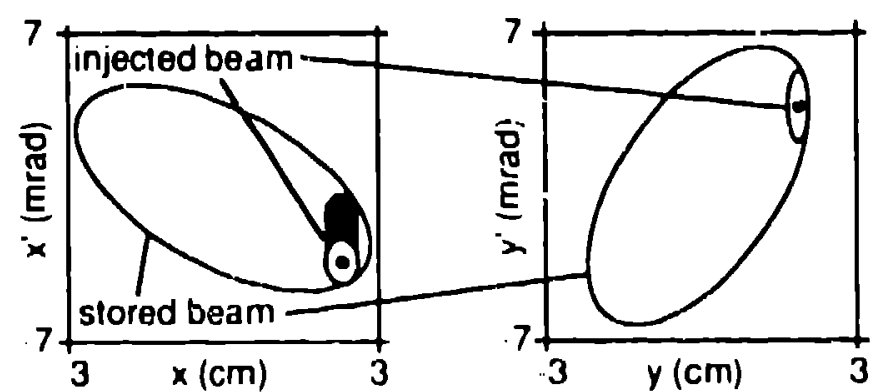

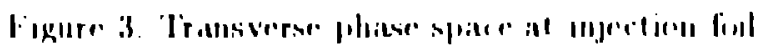

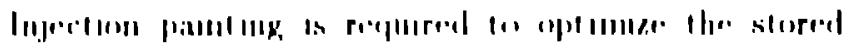

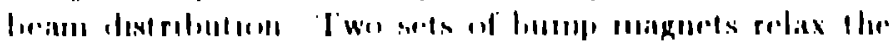

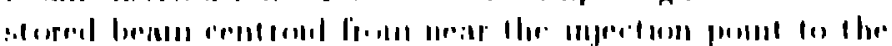

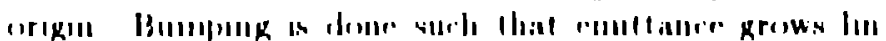

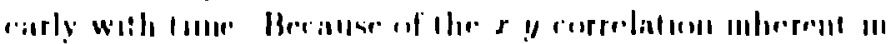

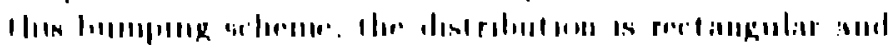

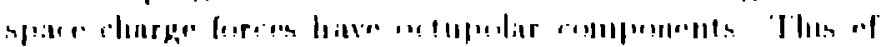

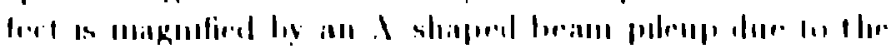

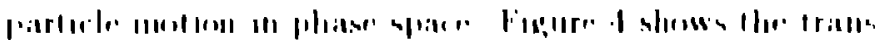

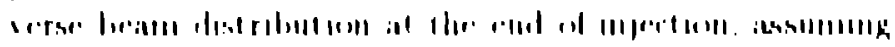

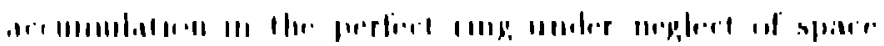

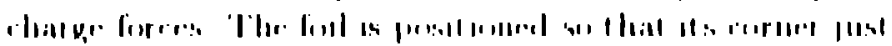

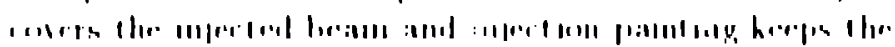

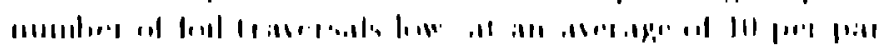
111.

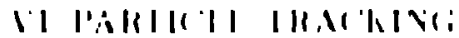

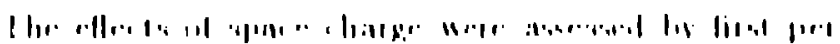

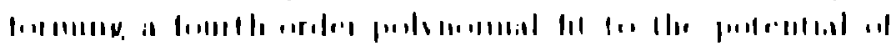

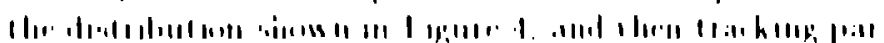

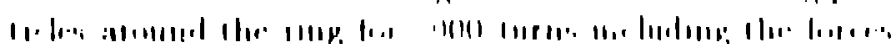

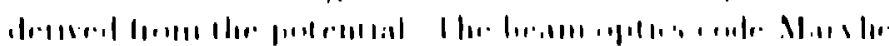

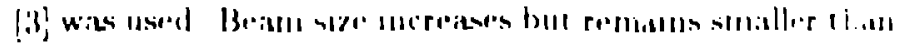
the physual aperture.

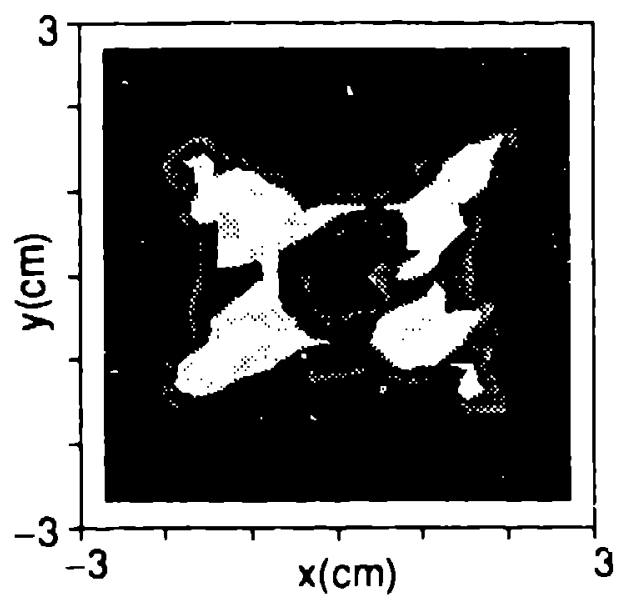

Figure I. Beam distribution al end of injectum

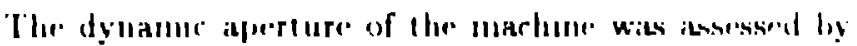
ingle partucle tracking to nimth order with the heatll-epllies

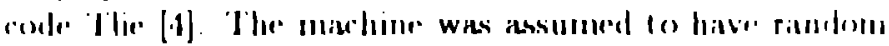

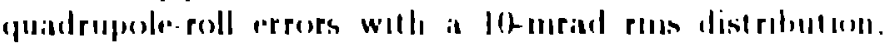

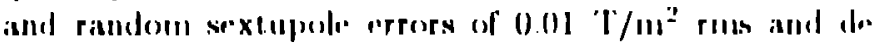

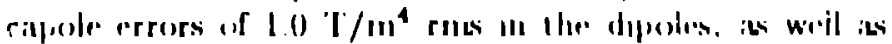

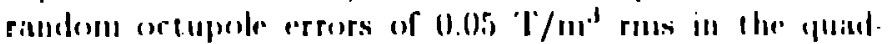

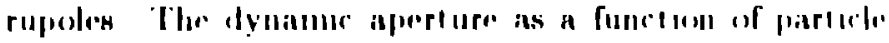

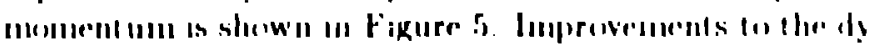
namie aprerenre will be mate using first and hepheremeler corrertore elemellits

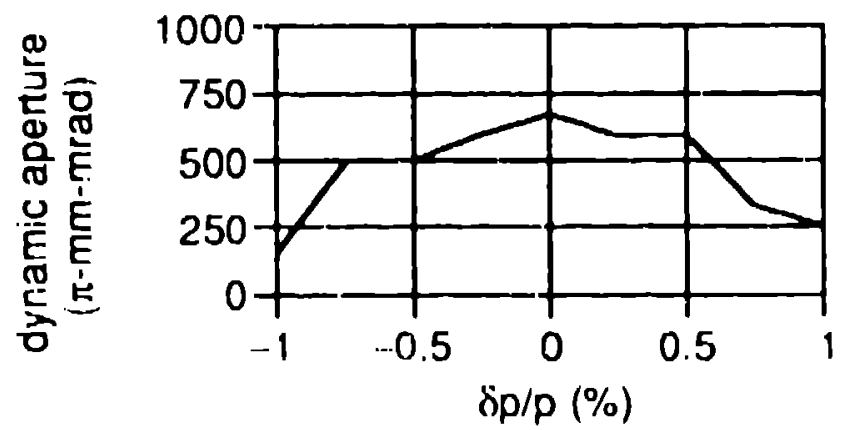

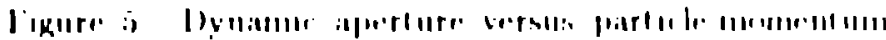
|lovill|ill

\section{NII HHHHINH}

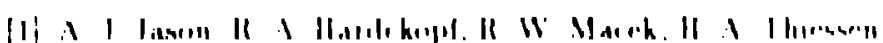

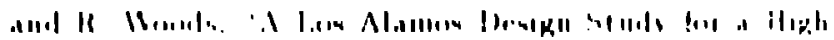

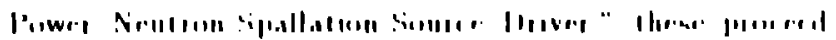
IIIR.

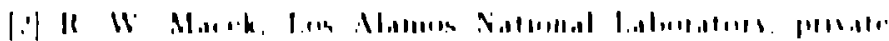
, IIIIIIII, al11,1

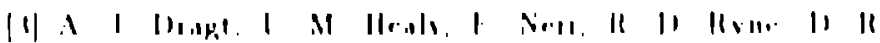

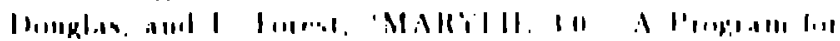

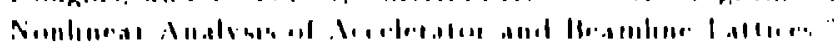

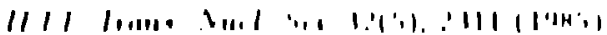

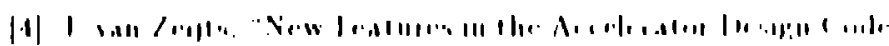

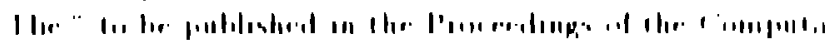

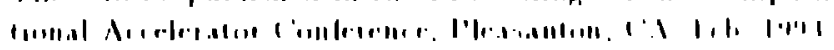

